\title{
A Rare Case of Hyper-Eosinophilic Syndrome Associated with Hydrocephalus and Erythroderma
}

\author{
Hesam Adin Atashi ${ }^{1}$, Hamid Zaferani Arani ${ }^{1}$, Babak Shazad ${ }^{2}$, Mahsa Mohammadi Bagheri ${ }^{3}$, Shahla \\ Abolghasemi ${ }^{4, *}$ and Seyyed Mojtaba Ghorani ${ }^{1}$ \\ ${ }^{1}$ School of Medicine, Tehran Medical Sciences, Islamic Azad University, Tehran, Iran \\ ${ }^{2}$ Department of Hematology Oncology, Tehran Medical Sciences, Islamic Azad University, Tehran, Iran \\ ${ }^{3}$ School of Medicine, Tehran University of Medical Sciences, Tehran, Iran \\ ${ }^{4}$ Department of Rheumatology, Tehran Medical Sciences Branch, Islamic Azad University, Tehran, Iran \\ "Corresponding author: Tehran Medical Sciences, Islamic Azad University, Tehran, Iran. Email: sh.abolghasemi@iautmu.ac.ir
}

Received 2020 September 12; Revised 2021 February 26; Accepted 2021 February 26.

Keywords: Hypereosinophilic Syndrome, Hydrocephalus, Erythroderma, Iran

\section{Dear Editor,}

Hyper-eosinophilic syndrome (HES) is defined by the presence of hypereosinophilia (blood eosinophilic count of $>1500$ cells $/ \mu \mathrm{L}$ and/or tissue hypereosinophilia) persisting for longer than one month; no identifiable etiology for eosinophilia and organ damage is directly attributable to the overproduction of eosinophils (1). In spite of the significant progress in the understanding of HES pathogenesis, our knowledge is insufficient for formulating a new comprehensive definition of HES based on its etiology (2). Erythroderma is an uncommon disorder that has a broad differential diagnosis and requires a high index of suspicion for treatment. Its varied underlying etiologies are in need of significantly different approaches to its treatment (3). To the best of our knowledge, only four cases of HES with erythroderma or cutaneous damage in adults have been previously reported in the literature (4-6). Indeed, no HES cases with hydrocephalus had been previously reported. We presented the first Iranian case of HES associated with hydrocephalus and erythroderma.

The patient was a 75-year-old Iranian man who presented flat, itchy, and painless red lesions on his trunk since July 2017. After visiting our hospital, complete blood count (CBC), differential blood count, liver function test (LFT), total and direct bilirubin, blood urea nitrogen (BUN), and creatinine $(\mathrm{Cr})$ tests were performed. The results showed eosinophilia in $\mathrm{CBC}$ with 3175 counts and total serum immunoglobulin E (IgE) levels (41.9 IU/mL; normal range 173), but the rest of the tests were normal. Then, a skin biopsy was performed from his trunk lesions, which showed eosinophils infiltration. After assessing the results, the dermatologist diagnosed him with erythroderma (Figures $1 \mathrm{~A}$ and $\mathrm{B}$ ) and prescribed a daily topical triamcinolone $0.5 \%$ for his lesions (7), which somewhat improved his skin lesions.

Six months later, the patient suddenly developed motion problem, and on examination, gate apraxia was found, and brain computed tomography (CT) showed dilation of the lateral ventricles (hydrocephalus). Following three times lumbar puncture procedure, the results of the LP fluid analysis were found to be normal; however, his motion problem did not recover (normal pressure hydrocephalus). A CBC test was performed, and 3128 counts of eosinophilia were discovered. Finally, one month after the rejection of other causes, the patient was diagnosed with HES based on the available evidence and eosinophilic counts of more than 1500 cells $/ \mu \mathrm{L}$. The patient took oral prednisolone ( $1 \mathrm{mg} / \mathrm{kg} /$ day) (8). However, this treatment did not result in his dramatic response; hence, we added hydroxyurea $(3 \mathrm{~g} /$ day) $(9,10)$ accompanied by MTX (17.5 mg single weekly dosage), folic Acid (1 mg/day), and golimumab (50 mg SC qMonth) (11). Two months later, his motion problem symptoms improved, and it led to a gradual reduction of redness in his skin. After taking brain CT, dilation of the cerebral ventricles had reduced. The brain CT scan showed lateral ventricular dilation (hydrocephalus) before treatment (Figure 1C) and decreased hydrocephalus after treatment (Figure 1D). Skin biopsies taken from the erythroderma before treatment showed hypereosinophilia surrounding connective tissue (Figure 1E) 

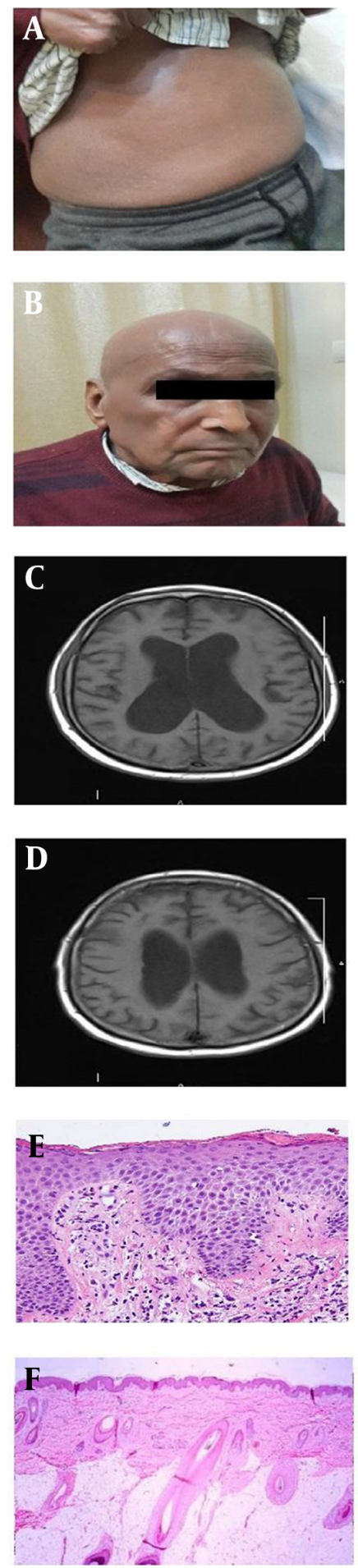

G

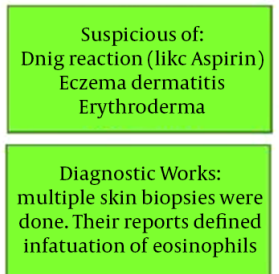

Physical Examination: Orthopcdic cxaminations were normal

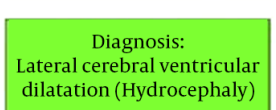
dilatation (Hydrocephaly)
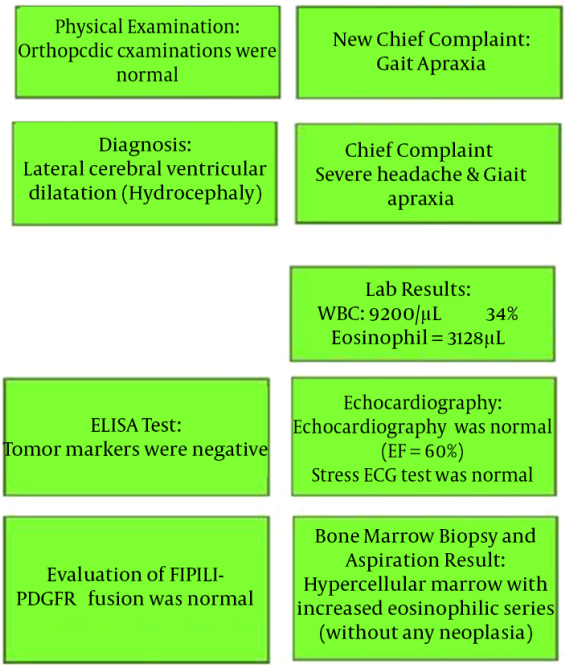

Lab Results: WBC: $9200 / \mu \mathrm{L} \quad 34 \%$ Eosinophil $=3128 \mu \mathrm{L}$

Echocardiography: Echocardiography was norm $(\mathrm{EF}=60 \%)$

Stress ECG test was normal

Bone Marrow Biopsy and Aspiration Result: Hypercellular marrow with increased eosinophilic serie (without any neoplasia)

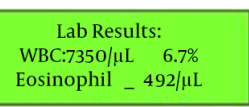

WBC: $7350 / \mu \mathrm{L} \quad 6.7 \%$ Eosinophil _ $492 / \mu \mathrm{L}$

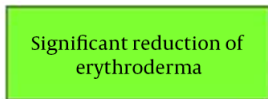

Complete cure of erythroderma motion problcm still cxists
No significant previous history
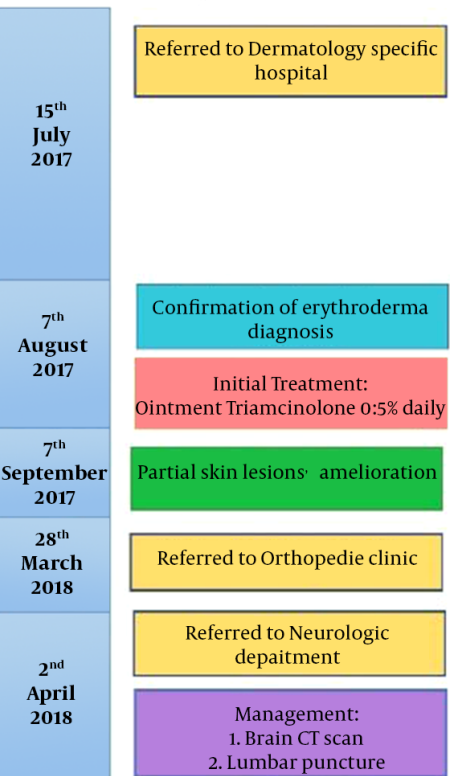

$27^{\text {th }}$

April

2018

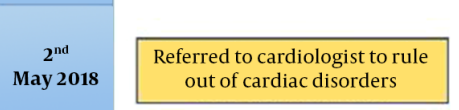
out of cardiac disorders

Management: Bone marrow biopsy and aspiration

$29^{\text {th }}$ May 2018

PCR of FIPILI-PDGFRagene

\section{Final Diagnosis: HES}

Regarding HES diagnostic cricria: Eosinophil $>1500 \mu \mathrm{L}: 2 . \geq 2$ tests in the period of at least 1 month: 3 . Tissue cosinophilia 4. Rule out oth causcs of Hypereosinophilia

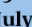

July Treatment:

Treatment:
Oral prednisolone $1 \mathrm{mg} / \mathrm{kg} /$ day Hydroxyurea 3g/day Mctbotrexate $17.5 \mathrm{mg}$ singlc dosc/week Folic acid 1mg/day Golimumab (50 mg SC qMonth) $9^{\text {th }}$

October 2018
Brain $\mathrm{CT}$ and lab tests were repcaicd

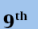

$9^{\text {th }}$

Decemb

Final follow up

Figure 1. Clinical data of a 75-year-old Iranian man. (A, B) Redness of the patient's entire body caused by erythroderma. (C, D) Severe hydrocephalus before the treatment depicted via the brain CT. (E, F) Skin biopsies taken from the erythroderma and an increased number of eosinophils reveals surrounding connective tissue before treatment and decreased number of eosinophils after treatment (haematoxylin and eosin, original magnification $\times 100)$. (G) The algorithm of our diagnostic process. 
and decreased number of eosinophils after treatment (Figure $1 \mathrm{~F})$.

Classification of HES, including lymphocytic HES, myeloproliferative HES, and idiopathic HES, is defined by eosinophilia in the blood and tissues or both (Table 1) (8). In the present case, all the causes of hypereosinophilia were ruled out. Thus, we tagged our patient in the subclass of idiopathic HES (9).

In a previous research (10), diagnostic criteria for HES were presented based on the studies of Chusid et al. and Simon et al. (2). These criteria include: (1) blood eosinophilic count of $\geq 1500$ cells $/ \mu$ L for a period of $>$ six consecutive months, (2) end-organ involvement and tissue eosinophilia, and (3) absence of any other known causes of hypereosinophilia. The clinical manifestations of HES associated with different organ damages are shown in Table 1.

In our case, the first presentation was the cutaneous symptom. At first, he had visited the hospital with a superficial diffused itching red lesions on his trunk. According to the studies of Heung et al. and Roufosse et al. (9), the differential diagnoses of hypereosinophilia include: (1) parasitic and fungal infectious diseases; (2) oncologic disease; (3) allergic disease; (4) endocrine disorders; (5) particular organ disorders, such as lungs, skin, vascular abnormality (Churg-Strauss syndrome), gastrointestinal symptom (eosinophil-associated gastrointestinal disease), etc.; and 6) immunologic diseases.

Cutaneous manifestations of HES required differential diagnosis with urticaria, pruritus sine materia, mycosis fungoides, cutaneous adverse drug reactions, contact dermatitis, and atopic dermatitis. Dermatologists should consider pruritic, erythematous papules, urticaria, angioedema, dermographism, oral and genital ulcers, centrifugal annular erythema, acral bullae, and erythroderma. Histopathologic examination of the skin lesion is usually nonspecific, with viable eosinophilic infiltration (12). For the initial diagnosis of our patient, we ruled out the above-mentioned disorders. Our performance algorithm ruled out clonal HES and confirmed idiopathic HES in our case (Figure $1 G$ ) (10). The diagnosis of HES is often delayed due to its pleomorphic dermatological manifestations and insidious evolution. It is thus crucial that in all cases of erythroderma, HES should be considered as a differential diagnosis (12).

Eosinophils have direct cytotoxicity through the local release of toxic substances, including cationic proteins, enzymes, reactive oxygen species, pro-inflammatory cytokines, and arachidonic acid derived factors. The de- gree of end-organ damage is heterogeneous, and there is often no correlation between the level or duration of eosinophilia and the severity of organ damage (13).

The causes of nervous involvement in HES are poorly understood. However, one of the possible reasons for hydrocephalus in our case could be the increased CSF release because of hypereosinophilia. Basically, eosinophils at the site of inflammation can produce a large number of cytokines and release lipid mediators and granule proteins like neurotoxin. These may affect the ependymal cells in the choroid plexuses of the brain ventricles and produce an excess amount of CSF (10). The titers of serum rheumatoid factors of ANA, ANCA, and dsDNA were negative. Antifungal parasitic immunoglobulin and IgE were measured, which were found to be negative as well. Regarding our management, bone marrow aspiration and biopsy were done for the analyses of cytology and gene mutation. Hypercellular bone marrow was associated with increased eosinophilic series (without any neoplasia). Using RT-PCR and FISH techniques (10), no mutations of FIP1L1-PDGFR $\alpha$ and PDGFR $\beta$ were observed, that is, there was no chromosomal deletion of the $\mathrm{CHIC} 2$ domain or gene deletion (fusion) of FIP1L1 and PDGFR $\alpha$ on chromosome 4 q12.

According to the patient's CBC/Diff laboratory tests and after ruling out other causes of hypereosinophilia, he was diagnosed with HES, leading to some complications like erythroderma and hydrocephalus. A few months after the treatments, his tests showed a reduction in eosinophil count and alleviated severities of erythroderma complications and the patient's hydrocephalus.

\section{Acknowledgments}

The authors are grateful to the patient who participated in this study.

\section{Footnotes}

Authors' Contribution: Study concept and design, H. A. A. and H. Z. A.; Drafting of the manuscript, B. S. and M. M. B.; Critical revision of the manuscript for important intellectual content, S. A., H. A. A, and S. M. G.; Study supervision, S. A.

Conflict of Interests: The authors declare that they have no competing interests.

Funding/Support: None declared.

Informed Consent: The patient has provided informed consent for publication of the case. 
Atashi HA et al.

\begin{tabular}{|c|c|}
\hline Subclasses of HES & Manifestations \\
\hline \multicolumn{2}{|l|}{ Myeloproliferative } \\
\hline PDGFR $\alpha$-related HES & $\mathrm{F} / \mathrm{P}^{\mathrm{b}}$ mutation defined by RT-PCR and FISH ${ }^{\mathrm{c}}$ \\
\hline Unknown etiology & No F/P mutation and clonal eosinophilia defined by HUMARA ${ }^{\mathrm{d}}$ PCR at Chromosome $\mathrm{X}$ \\
\hline Chronic eosinophilic leukemia & Presence of blasts on peripheral smear and/or cytogenetic anomalies \\
\hline Lymphocytic & Release of Th2 cytokines (like IL-5) \\
\hline \multicolumn{2}{|l|}{ PCR of T-cell receptor } \\
\hline \multicolumn{2}{|l|}{ Flow cytometry of clonal lymphocytes } \\
\hline \multicolumn{2}{|l|}{ Idiopathic } \\
\hline Benign & Without any organ involvements/asymptomatic \\
\hline Episodic & Eosinophilalia with cyclical angioedema \\
\hline \multirow[t]{2}{*}{ Complex } & With organ involvement, symptomatic, and not classified as myeloproliferative or lymphocytic HES \\
\hline & Signs \& Symptoms \\
\hline \multicolumn{2}{|l|}{ Clinical manifestations } \\
\hline General manifestations & A fever of $>38^{\circ} \mathrm{C}$, myalgia, arthralgia, asthenia, etc. \\
\hline Skin & Erythroderma. palpable purpura, livedo racemosa, urticaria, mucosal erosions, angioedema, etc., etc. \\
\hline Lung & Allergic asthma, rhinosinusitis, cough, dyspnea, RURI ${ }^{\mathrm{e}}$, pleural effusion, etc. \\
\hline Gastrointestinal & Abdominal pain, vomiting, diarrhea, ischemic colitis, ascites, etc. \\
\hline Neurologic impairment & Vertigo, paresthesia, aphasia, distal polyneuropathy, etc. \\
\hline Heart & Myocarditis, $\mathrm{MI}^{\mathrm{f}}$, valvular abnormalities, pericardial effusion, etc. \\
\hline Hematologic disorder & DVT $^{\mathrm{g}}$, anemia, superficial thrombophlebitis, elevation of serum IgE/tryptase/CRP, etc. \\
\hline \multicolumn{2}{|l|}{$\begin{array}{l}\text { a Platelet-derived growth factor receptor } \alpha \text {. } \\
\text { b } \text { FIP1L1/PDGFRA gene. } \\
{ }^{c} \text { Fluorescence in situ hybridization. } \\
{ }^{d} \text { Human androgen receptor gene. } \\
{ }^{e} \text { Recurrent upper respiratory infection. } \\
\text { f Myocardial infarction. } \\
{ }^{g} \text { Deep vein thrombosis. }\end{array}$} \\
\hline
\end{tabular}

\section{References}

1. Mankad R, Bonnichsen C, Mankad S. Hypereosinophilic syndrome: Cardiac diagnosis and management. Heart. 2016;102(2):100-6. doi: 10.1136/heartjnl-2015-307959. [PubMed: 26567231].

2. Simon HU, Rothenberg ME, Bochner BS, Weller PF, Wardlaw AJ, Wechsler ME, et al. Refining the definition of hypereosinophilic syndrome. J Allergy Clin Immunol. 2010;126(1):45-9. doi: 10.1016/j.jaci.2010.03.042. [PubMed: 20639008]. [PubMed Central: PMC3400024].

3. Bhatty O, Grant L, Shen J, Colanta A, Lauer S, Huerter C. Erythroderma: A rare complication of dyshidrotic eczema. Cureus. 2018;10(7). e3005. doi: 10.7759/cureus.3005. [PubMed: 30250767]. [PubMed Central: PMC6145800].

4. May LP, Kelly J, Sanchez M. Hypereosinophilic syndrome with unusual cutaneous manifestations in two men with HIV infection. J Am Acad Dermatol.1990;23(2 Pt 1):202-4. doi: 10.1016/0190-9622(90)70199r. [PubMed: 2145324].

5. Lee ML, Fischer G, Gow E. Hypereosinophilic syndrome presenting with erythroderma. Australas J Dermatol. 1988;29(2):95-101. doi: 10.1111/j.1440-0960.1988.tb00371.x. [PubMed: 2978638].

6. Lee $\mathrm{CH}$, Mamelak AJ, Vonderheid EC. Erythrodermic cutaneous T cell lymphoma with hypereosinophilic syndrome: Treatment with interferon alfa and extracorporeal photopheresis. Int J Dermatol. 2007;46(11):1198-204. doi: 10.1111/j.1365-4632.2007.03190.x. [PubMed: 17988344].

7. Chow S, Seow CS, Dizon MV, Godse K, Foong H, Chan V, et al. A clinician's reference guide for the management of atopic dermatitis in
Asians. Asia Pac Allergy. 2018;8(4). e41. doi:10.5415/apallergy.2018.8.e41. [PubMed: 30402408]. [PubMed Central: PMC6209602].

8. Das JK, Gupta K, Deshmukh S, Shrivastava R. A rare case of hypereosinophilic syndrome presenting with unilateral proptosis and torticollis. Indian J Ophthalmol. 2018;66(10):1508-11. doi: 10.4103/ijo.IJO_316_18. [PubMed: 30249857]. [PubMed Central: PMC6173005].

9. Klion AD, Bochner BS, Gleich GJ, Nutman TB, Rothenberg ME, Simon HU, et al. Approaches to the treatment of hypereosinophilic syndromes: A workshop summary report. J Allergy Clin Immunol. 2006;117(6):1292-302. doi: 10.1016/j.jaci.2006.02.042. [PubMed: 16750989].

10. Chen H, Raza HK, Jing J, Shen D, Xu P, Zhou S, et al. Hypereosinophilic syndrome with central nervous system involvement: Two case reports and literature review. Brain Inj. 2017;31(12):1695-700. doi: 10.1080/02699052.2017.1357835. [PubMed: 28945486].

11. Azuma N, Matsui K, Hashimoto N, Yoshikawa T, Sano H. Successful switch to golimumab for eosinophilia and skin symptoms related to multiple biologics in a patient with rheumatoid arthritis. Intern Med. 2017;56(12):1585-90. doi: 10.2169/internalmedicine.56.8168. [PubMed: 28626189]. [PubMed Central: PMC5505919].

12. Merlotto MR, Cantadori LO, Sakabe D, Miot HA. Case for diagnosis. Erythroderma as manifestation of hypereosinophilic syndrome. An Bras Dermatol. 2018;93(3):451-3. doi: 10.1590/abd1806-4841.20187419. [PubMed: 29924226]. [PubMed Central: PMC6001083].

13. Chang WL, Lin HJ, Cheng HH. Hypereosinophilic syndrome with recurrent strokes: A case report. Acta Neurol Taiwan. 2008;17(3):184-8. [PubMed: 18975525]. 